\title{
(Des) Ilusão da notícia: análise da construção da ilusão e da desilusão pela mídia na cobertura sobre o caso da fosfoetanolamina sintética
}

(Des) Ilusión de la noticia: análisis de la construcción de ilusión e decepción por parte de los medios de comunicación en la cobertura del caso de la fosfoetanolamina sintética

\section{(Des) Illusion of the news: analysis of the illusion and delusion construction by the media in the coverage of the synthetic phosphoethanolamine case}

\author{
Ana Carolina Pontalti Monari ${ }^{1}$ \\ Universidade Estadual Paulista (Brasil) \\ capmonari@gmail.com \\ Claudio Bertolli Filho ${ }^{2}$ \\ Universidade Estadual Paulista (Brasil) \\ claudio.bertolli@unesp.br
}

Fecha de recepción: 20 de agosto de 2019

Fecha de recepción evaluador: 21 de agosto de 2019

Fecha de recepción corrección: 29 de agosto de 2019

\footnotetext{
${ }^{1}$ Ana Carolina Pontalti Monari é jornalista e mestre em Comunicação pela Universidade Estadual Paulista (Unesp). Realiza pesquisas na área de mídia e saúde pública. https://orcid.org/0000-0002-7474-7903

2 Claudio Bertolli Filho é doutor em Ciências (História Social) pela Universidade de São Paulo (USP) e é livredocente na área de Antropologia pela Universidade Estadual Paulista (Unesp). É professor adjunto aposentado na Unesp, atuando junto ao Programa de Pós-Graduação em Comunicação. Realiza pesquisas na área da Comunicação e da História e Ciências Sociais aplicadas à Medicina. http://orcid.org/0000-0003-3584-9736
} 


\title{
Resumo
}

Este artigo tem como objetivo analisar a construção da ilusão e da desilusão da notícia por meio da cobertura sobre a fosfoetanolamina sintética produzida pelo G1 - São Carlos e Araraquara, empresa jornalística afiliada à Rede Globo, a maior empresa de comunicação do Brasil. Com a utilização de autores como Beck (2018), Motta (2002) e Lippmann (2008), além da utilização das metodologias de análise de conteúdo (Bardin, 2016) e da hermenêutica de profundidade (Thompson, 1995), este estudo concluiu que o portal de notícias promoveu, primeiramente, a criação de uma ilusão de que a substância poderia, de fato, trazer benefícios para o tratamento contra o câncer ou, até mesmo, a cura desta doença; posteriormente, no entanto, o site passou a dar prioridade para elementos negativos sobre a droga com suposto efeito medicamentoso, o que contribuiu para a construção de uma desilusão das instâncias políticas, científicas e médicas, além da opinião pública.

Palavras-chave: Mídia, ilusão e desilusão da notícia, saúde pública, fosfoetanolamina sintética.

\section{Resumen}

Este artículo tiene como objetivo analizar la construcción de la ilusión y decepción de las noticias a través del caso de la fosfoetanolamina sintética, producida por G1 - São Carlos e Araraquara, una empresa periodística afiliada a Rede Globo, la compañía de medios más grande de Brasil. Utilizando autores como Beck (2018), Motta (2002) y Lippmann (2008), además del uso de las metodologías de análisis de contenido (Bardin, 2016) y hermenéutica profunda (Thompson, 1995), este estudio concluyó que el portal de noticias primero promovió creando uma ilusión de que la sustancia prodría traer beneficios al tratamiento del cáncer o incluso curarlo; más tarde, sin embargo, el sitio dio prioridad a elementos negativos sobre la droga, lo que contribuyó a la desilusión de instancias políticas, científicas y médicas, así como a la opinión pública.

Palabras clave: Medios de comunicación, ilusión y desilusión de noticias, salud pública, fosfoetanolamina sintética.

\begin{abstract}
This article aims to analyze the construction of the illusion and delusion of the news through the synthetic phosphoethanolamine coverage produced by G1 - São Carlos e Araraquara, a journalistic company affiliated to Rede Globo, the largest media company in Brazil. Authors such as Beck (2018), Motta (2002) and Lippmann (2008) were used in this study, as well as the content analysis (Bardin, 2016) and the depth hermeneutics methodology (Thompson, 1995). The research concluded that the news portal first created an illusion that the substance could bring benefits to cancer treatment or cure it; later, however, the site gave priority to negative elements about the drug, which contributed to the disillusionment of political, scientific and medical instances, as well as public opinion.
\end{abstract}


Keywords: Media, illusion and delusion of news, public health, synthetic phosphoethanolamine.

\section{Introdução}

As dificuldades de entendimento e aceitação do mundo tal como ele se apresenta têm se acentuado na modernidade tardia a ponto de, tanto na esfera individual quanto coletiva, vivenciar-se o cotidiano, seus limites e suas potencialidades a partir de um prisma que associa em uma mesma equação o incômodo dos eventos corriqueiros e os desejos e idealizações, tanto daqueles que produzem quanto dos que consomem as notícias. Fala-se, pois, na disposição de avaliação dos fatos a partir de uma perspectiva que flutua entre o real e o imaginário, o qual em um primeiro momento nutre infinitas ilusões para, em seguida, rumar para o campo das desilusões.

Frente a este movimento, quando uma ilusão nutrida inicialmente pela mídia se aproxima do esgotamento, seguem-se reações ambíguas. Para alguns, aferrados ao imaginário, a ilusão perpetua-se como uma verdade incontestável e qualquer rejeição a uma ideia se constitui em uma espécie de "sabotagem", geralmente creditada a interesses econômicos. Para outros, no entanto, se a mídia endossou por algum tempo uma fantasia, o engodo se deve a fatores igualmente de ordem econômica - como o de ampliar a venda de seus produtos - ou por se alinhar a uma determinada ideologia ou a interesses escusos.

Para além dessas conclusões em algum grau simplistas, pensa-se que tanto a produção quanto o consumo das notícias constituem-se em operações antropologicamente significativas. Restringindo-se exclusivamente ao processo de elaboração das notícias, pensa-se estas como frutos da percepção consciente e inconsciente de um fato por parte de um jornalista ou por um grupo destes. Para o profissional da mídia, explicar e disseminar uma informação é reconhecer o "valor-notícia" de um acontecimento e explorá-lo textualmente sob o crivo da objetividade e da isenção de valores e interesses. Ao escrever, no entanto, o jornalista evidencia sua condição de sujeito envolvido pelas teias culturais, o que o condena a deixar indícios em seu texto tanto do logos - a razão, o fato histórico - quanto do mythos - a fantasia, a subjetividade.

A partir dessas considerações, avalia-se a notícia como um sistema simbólico peculiar que, apesar do compromisso de seu autor com a reprodução mais coerente possível da realidade, flutua entre o real e o ficcional. Nesse sentido, de acordo com Motta (2002a, p. 2), a notícia lida com a ambiguidade dos conflitos humanos, com as incertezas e as inseguranças do ser diante dos enigmas da humanidade e da natureza. Para o autor, as características do acontecimento jornalístico são a imprevisibilidade, a excepcionalidade e a aparente falta de nexo entre os fenômenos e, portanto, por sua própria natureza esses acontecimentos são perturbadores e inquietantes porque estão carregados de emoções, tensões e angústias. 
A operação que tenta buscar harmonia entre "aquilo que é" e aquilo que "queremos que fosse" impregna o ato jornalístico" (Motta, 2002b, p. 13). A mescla textual entre o logos e o mythos ganha densidade maior na abordagem de alguns temas considerados estratégicos para sobrevivência humana, especialmente os referentes aos fatos científicos, um dos eixos privilegiados pelo jornalismo a ponto de aflorar como uma especialidade da profissão.

No referente à ciência, cabe notar que a mídia atua no setor a partir de diferentes níveis culturais, fazendo fluir versões contrastantes sobre o que é realizado nos laboratórios. Segundo Beck (2018), a modernidade tardia deu vasão a duas dimensões de avaliação dos produtos contemporâneos. Por um lado, a "sociedade da segurança" entende as "novidades", inclusive científicas, como a estratégia perfeita para o aperfeiçoamento do Homem e do Mundo, alimentando fantasias sobre o gradual aperfeiçoamento da sociedade e da vida individual e, por outro, a "sociedade de risco", que observa com cautela as mesmas inovações, frequentemente rejeitando-as como propostas danosas para a Humanidade, ou mesmo propostas conscientemente falsas. Entre um e outro tipo de "sociedade", a cultura flui e seus traços impregnam a escrita jornalística.

A partir desse cenário, o objetivo deste texto é avaliar a construção da ilusão e da desilusão por meio da produção jornalística sobre a fosfoetanolamina sintética, uma substância que, em um certo momento, foi apresentada pela imprensa como uma possível droga que curaria ou, pelo menos, alongaria a vida dos cancerosos para, em seguida, denunciar o composto químico como inócuo ou perigoso para o paciente oncológico.

O corpus adotado para a investigação consiste nas reportagens produzidas pelo G1 - São Carlos e Araraquara, site de notícias vinculado à EPTV, afiliada à Rede Globo, a principal empresa de comunicação do Brasil, no período de agosto de 2015 a julho de 2016. No período focado, foram produzidas 48 reportagens jornalísticas que obtiveram grande repercussão, sendo, inclusive, utilizadas pela mídia televisiva da Rede Globo, o que ampliou a repercussão dos fatos apresentados.

Antes da avaliação da documentação selecionada, duas questões precisam ser discutidas: a primeira refere-se à significância do câncer como questão de saúde pública no Brasil e a outra consiste no que, de fato, é a fosfoetanolamina sintética e o contexto em que estava sendo produzida no país.

\section{Referencial teórico}

\section{O câncer e as angústias contemporâneas}

Os jornalistas se utilizam de mecanismos de sua profissão para representar ações, atitudes e comportamentos que estão presentes na sociedade. Eles são importantes 
agentes na construção de pensamentos sobre determinados temas e ajudam a influenciar os assuntos que irão circular na opinião pública (Lippmann, 2008).

Desse modo, a construção de ideias parte do pressuposto de que o conhecimento está baseado em reconstruções, releituras e na transformação da realidade em um problema. Morin (2004) argumenta que todo o saber se constitui, ao mesmo tempo, em uma tradução e uma reconstrução, a partir de signos, sinais e símbolos, sob a forma de representações, ideias, teorias e discursos.

É possível, portanto, compreender que há uma longa trajetória de como a mídia dá atenção ao câncer. Siddhartha Mukherjee (2012) define a enfermidade como sendo um "crescimento descontrolado de uma única célula. Esse crescimento é deflagrado por mutações - mudanças no DNA que afetam especificadamente os genes estimuladores do crescimento ilimitado das células" (Mukherjee, 2012, p. 22).

As neoplasias apresentam características que variam de pessoa para pessoa e também de órgão para órgão - por exemplo, o tumor de laringe pode não apresentar os mesmos elementos de um carcinoma localizado na mama. Por isso, além do fato de não apresentar cura para todos os seus tipos, a enfermidade transformou-se em espécie de tabu na sociedade, principalmente por sua trajetória estar entrelaçada à morte.

Embora o carcinoma pareça ser um problema atual de saúde pública, com políticas governamentais próprias e específicas para sua cura ou tratamento, o seu surgimento é antigo. De acordo com Mukherjee (2012), o termo câncer apareceu pela primeira vez na literatura médica no ano de 400 a. C., com o relato do historiador grego Heródoto sobre Atossa, rainha da Pérsia, que teria sido acometida por essa doença.

Durante toda a Idade Antiga e a Idade Média, o carcinoma foi associado ao desespero e à morte $\mathrm{e}$, por isso, muitos cidadãos recorreriam à medicina alternativa, em larga escala baseada em práticas mágico-religiosas, como uma forma de tratamento para este mal. Foi somente em meados do século XIX, com o advento da teoria celular, que a doença começou a ser explicada como um fenômeno patológico ocorrido no interior das células e que o mal era impossível de ser tratado pela medicina, definindo-se assim como uma doença mortal. Em larga dose, o sentimento de incurabilidade ainda é vivenciado no século XXI tanto por leigos quanto por especialistas, pois mesmo com os avanços da ciência e das terapêuticas, o câncer ainda representa um difícil desafio para a medicina moderna.

Em 2019, o Instituto Nacional do Câncer (Inca) estima que o Brasil irá registrar 600 mil novos casosi da doença. A Organização Mundial da Saúdeii, por outro lado, acredita que o número de ocorrências deve aumentar em $50 \%$ no ano de 2025 , em decorrência do envelhecimento da população - atualmente, segundo o órgão, o câncer é a segunda causa de morte no país (63 mil mortes/ano).

A questão do medo de estar doente, ou de algum familiar ou amigo próximo manifestar a enfermidade, é apresentada pelos veículos de comunicação, por meio de seus 
discursos. Fausto Neto (1999) afirma que esse processo se dá pela instância da fala, uma vez que a mídia organiza essa circulação de palavras segundo a lógica da noção de atualidade. Para ele, a imprensa transforma comentários públicos e privados em um discurso público, mas que é privatizado de acordo com determinadas condições de produção de cada instituição dentro do campo jornalístico, de onde é possível concluir que a noção de publicização está cada vez mais subordinada a operações/articulações de construção discursiva de cada dispositivo de produção de sentido.

O jornalista, portanto, ao informar sobre o câncer leva, por meio do seu texto, anseios, medos e esperanças em relação à temática, uma vez que o ato de informar carrega representações, ações, atitudes e comportamentos que lhe são intrínsecos. Este profissional, afinal, faz parte da sociedade em que vive e também teme ser acometido pelo câncer ou receia que algum familiar/amigo receba o diagnóstico dessa doença.

A esperança de obtenção de uma possível cura para a neoplasia está presente na cobertura jornalística, por meio de notícias sobre novos tratamentos ou medicamentos que possam oferecer benefícios aos pacientes. A fosfoetanolamina sintética foi um dos exemplos mais recentes dessas "apostas" da mídia, uma vez que a imprensa criou a narrativa de que o produto químico supostamente poderia erradicar ou trazer melhorias significativas aos portadores da enfermidade.

\section{O contexto histórico e midiático da fosfoetanolamina sintética}

A fosfoetanolamina sintética foi desenvolvida na década de 1990 pela equipe do professor Gilberto Chierice nos laboratórios do Instituto de Química de São Carlos (IQSC), da Universidade de São Paulo (USP), em São Carlos. Com a proposta de oferecer melhorias no tratamento contra o câncer, o composto químico chegou a ser estudado nas dependências do Hospital Amaral Carvalho (HAC), em Jaú (SP), uma das principais instituições nacionais que oferece tratamento e apoio social e psicológico às vítimas de câncer, mas a parceria foi desfeita ainda no início dos anos 2000.

No Brasil, qualquer substância com fins medicamentosos necessita ser submetida à testes clínicos antes de ser comercializada, obtendo para isso um registro na Agência Nacional de Vigilância Sanitária (Anvisa). O fato de não ter certificação na Anvisa, no entanto, não impediu sua distribuição para os cidadãos comuns. Durante cerca de 20 anos, pacientes portadores de câncer recorreram ao IQSC para obter as cápsulas e propagaram seus relatos sobre o uso da substância, sobretudo, na internet.

Em 2014, a USP publicou uma portaria que impedia que qualquer droga com fins medicamentosos fosse distribuída nas dependências do IQSC. Frente ao veto da universidade, os pacientes que antes contavam com livre acesso à substância buscaram novas maneiras de dar continuidade ao tratamento, o qual foi classificado como "alternativo" por não contar com apoio e legitimação pela maior parte da comunidade científica. Eles ingressaram com ações na Justiça do Estado de São Paulo e o alto volume de processos chamou a atenção do G1 - São Carlos e Araraquara, que publicou a 
primeira reportagem sobre o caso em agosto de 2015. Com isso, o portal se transformou em pioneiro na informação sobre assunto, tornando-se referência para os demais veículos de comunicação que passaram a cobrir os eventos tematizados pela droga que começou a ser denominada "pílula do câncer".

Com a grande repercussão gerada pela mídia, a "pílula do câncer" foi alvo de medidas judiciais pró e contra a sua distribuição por juízes de primeira e segunda instâncias, além de se tornar um tema a ser debatido pelo Supremo Tribunal Federal (STF). A droga também chamou a atenção da esfera política em diversos âmbitos: alguns deputados federais se organizaram, discursando na plenária da Câmara e do Senado e elaborando projetos de lei que objetivavam dar prosseguimento aos testes clínicos e/ou viabilizar a continuidade de distribuição da droga para os pacientes portadores de neoplasias. Nessas circunstâncias tomadas por controvérsias científicas, médicas e farmacêuticas, entre outras, algumas vozes defendiam que seriam necessárias novas e mais extensas pesquisas para que fosse possível comprovar que a fosfoetanolamina sintética poderia ser, de fato, um tratamento eficaz contra tumores.

Respondendo aos reclamos sociais sobre a liberação da substância, o governo do Estado de São Paulo realizou os primeiros testes clínicos com seres humanos em 2016, no Instituto do Câncer do Estado de São Paulo (Icesp). Os resultados, entretanto, não foram satisfatórios para os pesquisadores responsáveis pelo composto químico, uma vez que se comprovou que a substância não era eficaz contra todos os tipos de câncer. $\mathrm{O}$ estudo foi alvo de uma Comissão Parlamentar de Inquérito (CPI), na Assembleia Legislativa de São Paulo (Alesp), que concluiu em 2018 que o protocolo de pesquisa não foi seguido à risca, apresentando diversas falhas, tais como o emprego de pacientes com comorbidades e a recorrência a procedimentos experimentais que se interpuseram como "embaraços" ou obstruções, desencadeando nos resultados insatisfatórios.

A Alesp sugeriu a execução de novos testes clínicos, mas até agosto de 2019 não houve interesse do governo estadual em promover novas pesquisas. A Universidade Federal do Ceará (UFC), no entanto, divulgou em junho de 2019 que iria iniciar os estudos sobre a fosfoetanolamina sintética com seres humanos, mas os dados da investigação ainda não foram divulgados.

\section{Metodologia}

Para verificar como se constrói a ilusão e a desilusão pela mídia sobre a fosfoetanolamina sintética, este estudo se utilizou de duas metodologias de pesquisas: a análise de conteúdo (Bardin, 2016) e a hermenêutica de profundidade (Thompson, 1995).

A análise de conteúdo pode ser considerada como:

"Um conjunto de técnicas de análise das comunicações visando obter por procedimentos sistemáticos e objetivos de descrição do conteúdo das mensagens indicadores (quantitativos ou não) que permitam a inferência de conhecimentos relativos às condições de produção/recepção (variáveis indeferidas) dessas mensagens" (Bardin, 2016, p. 48). 
A análise de conteúdo leva em consideração as significações (conteúdo), eventualmente sua forma e a distribuição desses conteúdos e formas (índices formais e análise de coocorrência). Há diversas maneiras de se aplicar essa metodologia, porém, "a maior parte das técnicas propostas é do tipo temático e frequencial (o método mais fácil, mais conhecido e mais útil numa primeira fase de abordagem da maioria dos materiais)" (Bardin, 2016, p. 55).

Este estudo priorizou, justamente, o uso das técnicas do tipo temática e frequencial aliadas à hermenêutica de profundidade abordada por Thompson (1995), que afirma que este referencial coloca em evidência o fato de que o objeto de análise é uma construção simbólica significativa, que exige uma interpretação. Segundo o autor mencionado, a hermenêutica de profundidade pode ser compreendida em três fases ou procedimentos principais: análise sócio-histórica, análise formal ou discursiva $\mathrm{e}$ interpretação/reinterpretação. O objetivo da primeira etapa é reconstruir as condições sociais e históricas de produção, circulação e recepção das formas simbólicas; o propósito da segunda é reconstituir e tornar explícitos os padrões de inferência que caracterizam o discurso; e a terceira e última fase busca criar uma construção criativa do significado, ou seja, uma explicação interpretativa do que está sendo representado (Thompson, 1995). Os dados obtidos com o auxílio dessas duas metodologias foram, posteriormente, analisados e confrontados com as teorias científicas expostas neste texto.

\section{Resultados e discussão dos dados:}

\section{Construção da ilusão e da desilusão pela mídia}

Em um primeiro momento, as notícias sobre o caso produzidas pelo $G 1-S \tilde{o} o$ Carlos e Araraquara foram submetidas à análise de conteúdo em duas categorias: reportagens positivas sobre a fosfoetanolamina sintética e reportagens negativas sobre a fosfoetanolamina sintética. Os dados foram sintetizados em formato de tabela, como pode ser visto a seguir.

Tabela 1. Reportagens publicadas pelo G1 - São Carlos e Araraquara sobre a fosfoetanolamina sintética

\begin{tabular}{|c|c|c|}
\hline $\begin{array}{l}\text { Mês/Ano de } \\
\text { publicação }\end{array}$ & $\begin{array}{llll}\text { Reportagens positivas } & \text { sobre } & \text { a } \\
\text { fosfoetanolamina sintética } & & \\
\end{array}$ & 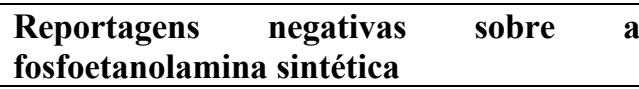 \\
\hline $08 / 2015$ & $\begin{array}{l}\text { Pacientes pedem na Justiça que USP } \\
\text { forneça cápsula de combate ao câncer; } \\
\text { Pesquisador acredita que substância } \\
\text { desenvolvida na USP cura o câncer; } \\
\text { E-mail mostrou interesse da Fiocruz } \\
\text { cápsula de combate ao câncer. }\end{array}$ & $\begin{array}{l}\text { "Consciência em paz", afirma homem preso } \\
\text { por doar cápsula contra câncer. }\end{array}$ \\
\hline $09 / 2015$ & $\begin{array}{l}\text { Cresce o } n^{\circ} \text { de pessoas que entram na } \\
\text { Justiça em busca de cápsula da USP. }\end{array}$ & $\begin{array}{l}\text { TJiv suspende mais de } 360 \text { liminares para } \\
\text { entrega de fosfoetanolamina. }\end{array}$ \\
\hline $10 / 2015$ & $\begin{array}{l}\text { Reunião de pesquisadores e políticos } \\
\text { discute substância contra o câncer; }\end{array}$ & $\begin{array}{l}\text { TJ barra mais liminares e pacientes recorrem } \\
\text { para obter cápsulas da USP; }\end{array}$ \\
\hline
\end{tabular}




\begin{tabular}{|c|c|c|}
\hline & $\begin{array}{l}\text { Alckmin v diz que vai conversar com o } \\
\text { secretário sobre a fosfoetanolamina; } \\
\text { STF determina entrega de cápsulas da } \\
\text { USP para pacientes com câncer no Rio; } \\
\text { Filho busca cápsulas na USP após } \\
\text { liberação do STF: "Não tem preço"; } \\
\text { Presidente do TJ-SP volta atrás e libera } \\
\text { entrega de fosfoetanolamina; } \\
\text { Com filas, USP distribui senhas para } \\
\text { fornecer substância contra câncer; } \\
\text { USP diz que cápsulas contra o câncer } \\
\text { serão enviadas a pacientes por Correios. }\end{array}$ & $\begin{array}{l}\text { Justiça amplia prazo da USP para entrega de } \\
\text { fosfoetanolamina sintética. }\end{array}$ \\
\hline $11 / 2015$ & $\begin{array}{l}\text { Manifestação em São Carlos pede a } \\
\text { liberação e o acesso à fosfoetanolamina; } \\
\text { "É uma esperança", diz mulher com } \\
\text { câncer em ato da fosfoetanolamina. }\end{array}$ & $\begin{array}{l}\text { Conselho de Farmácia autua a USP por } \\
\text { produção de fosfoetanolamina; } \\
\text { Desembargadores do TJ suspendem entrega } \\
\text { de fosfoetanolamina. }\end{array}$ \\
\hline $12 / 2015$ & $\begin{array}{l}\text { Sem produção de princípios ativos, Furp }{ }^{\text {vi }} \\
\text { deverá encapsular fosfoamina. }\end{array}$ & $\begin{array}{l}\text { "Não tinha higiene", diz delegado sobre } \\
\text { laboratório ilegal de fosfoetanolamina; } \\
\text { Laudo aponta que fosfoetanolamina vendida } \\
\text { em Conchal, SP, é falsificada; } \\
\text { Vídeo mostra prisão de suspeito de } \\
\text { comercializar fosfoetanolamina falsa; } \\
\text { Justiça bloqueia contas de trio preso por } \\
\text { vender suposta fosfoetanolamina; } \\
\text { Pelo menos } 5 \text { mil pessoas estão sem } \\
\text { fosfoetanolamina, diz levantamento; } \\
\text { Agressão faz USP mudar o local de demandas } \\
\text { sobre a fosfoetanolamina. }\end{array}$ \\
\hline $01 / 2016$ & & $\begin{array}{l}\text { Polícia Civil indicia } 4 \text { envolvidos na venda de } \\
\text { suposta fosfoetanolamina. }\end{array}$ \\
\hline $02 / 2016$ & $\begin{array}{l}\text { Manifestação pela liberação da "pílula do } \\
\text { câncer" reúne mais de } 300 \text { pessoas; } \\
\text { Laboratório em Cravinhos, SP, vai } \\
\text { sintetizar fosfoetanolamina para testes. }\end{array}$ & \\
\hline $03 / 2016$ & $\begin{array}{l}\text { Comissão aprova realização de testes da } \\
\text { fosfoetanolamina em humanos; } \\
\text { Manifestantes pedem a liberação da } \\
\text { fosfoetanolamina sintética em Leme; } \\
\text { Laboratório de Cravinhos se prepara para } \\
\text { a produção da fosfoetanolamina. }\end{array}$ & $\begin{array}{l}\text { Pesquisador vê os primeiros testes da } \\
\text { fosfoetanolamina como "equivocados"; } \\
\text { Mesmo com ordens judiciais, USP de São } \\
\text { Carlos não entrega a "pílula do câncer"; } \\
\text { USP denuncia pesquisador que criou a "pílula } \\
\text { do câncer" por curandeirismo; } \\
\text { USP continua descumprindo ordem judicial e } \\
\text { não entrega "pílula do câncer". }\end{array}$ \\
\hline $04 / 2016$ & & $\begin{array}{l}\text { USP manda fechar laboratório de São Carlos } \\
\text { que produz fosfoetanolamina; } \\
\text { Com } 14 \text { mil ações pedindo a "pílula do } \\
\text { câncer", USP alega não poder produzir; } \\
\text { Pesquisadores da "pílula do câncer" } \\
\text { contestam testes do MCTIvii no Senado; } \\
\text { "Profunda preocupação", diz Anvisa sobre a } \\
\text { liberação da fosfoetanolamina; } \\
\text { Polícia não vê indícios de crimes por químico } \\
\text { que criou a fosfoetanolamina. }\end{array}$ \\
\hline $05 / 2016$ & $\begin{array}{l}\text { Pacientes protestam pela liberação da } \\
\text { "pílula do câncer" em São Carlos, SP. }\end{array}$ & $\begin{array}{l}\text { Pesquisador diz que não vai autorizar a venda } \\
\text { da "pílula do câncer"; } \\
\text { TRFviii de SP suspende fornecimento da } \\
\text { "pílula do câncer" no estado e em MSix; } \\
\text { Suspensão da lei da "pílula do câncer" vai } \\
\text { dificultar acesso, dizem advogados; } \\
\text { "Não tem outra opção", diz filho que tenta } \\
\text { fosfoetanolamina para mãe. }\end{array}$ \\
\hline
\end{tabular}




\begin{tabular}{|l|l|l|}
\hline $06 / 2016$ & $\begin{array}{l}\text { Pesquisador autoriza laboratório de } \\
\text { Cravinhos a produzir "pílula do câncer". }\end{array}$ & \\
\hline $07 / 2016$ & & $\begin{array}{l}\text { USP abre sindicância para investigar } \\
\text { pesquisador da fosfoetanolamina. }\end{array}$ \\
\hline $\begin{array}{l}\text { Total de } \\
\text { inserções }\end{array}$ & 21 inserções & 27 inserções \\
\hline
\end{tabular}

Fonte: elaborado pelos autores.

Os dados obtidos por meio da análise de conteúdo (Bardin, 2016) indicam que o G1 - São Carlos e Araraquara priorizou informar conteúdos negativos sobre a fosfoetanolamina sintética durante o primeiro ano de cobertura sobre o caso, que compreende o período de agosto de 2015 a julho de 2016 - momento em que a "pílula do câncer" foi apresentada ao público-leitor até o início dos testes clínicos promovidos pelo Instituto do Câncer do Estado de São Paulo (Icesp). O portal de notícias regional publicou 48 reportagens sobre o caso nesse período, sendo que 27 notícias ofereciam informações negativas sobre o composto e 21 traziam aspectos a favor da substância química.

É possível observar - apenas verificando os títulos das reportagens publicadas pelo site - que a maneira como a fosfoetanolamina sintética foi apresentada ao público-leitor mudou conforme o tempo. Entre agosto e outubro de 2015, o composto químico era citado como sendo uma droga "contra o câncer" (agosto de 2015); de "combate ao câncer" (agosto de 2015); a "cápsula da USP" (agosto e setembro de 2015); as “cápsulas contra o câncer" (outubro de 2015); e a "substância contra o câncer" (outubro de 2015). A partir de novembro de 2015, entretanto, o composto químico passou a ser divulgado para o público apenas pelo seu nome científico - fosfoetanolamina sintética - ou por "pílula do câncer".

Essa mudança de tratamento, coincidentemente ou não, deu-se a partir de meados de outubro, após a veiculação de uma reportagem no Fantástico $^{x}$ - revista eletrônica semanal produzida e transmitida nacionalmente pela Rede Globo, grupo do qual o G1 São Carlos e Araraquara faz parte. Diferentemente do que vinha sendo adotado pelo portal regional desde o início, o conteúdo do Fantástico apresentava um tom negativo ao composto químico e ganhou respaldo científico na figura do médico oncologista, cientista e escritor Drauzio Varella, que é consultador na área de saúde do programa televisivo. No mês seguinte a matéria da revista eletrônica semanal, o site sediado em São Carlos (SP) passou a adotar o mesmo tipo de opinião perante o caso, abdicando assim de fazer referências positivas à droga.

Nos primeiros meses, entrevistas com os pesquisadores responsáveis pelo suposto medicamento também foram realizadas e acrescentadas no texto jornalístico, bem como falas de especialistas na área da saúde, membros da Agência Nacional de Vigilância Sanitária (Anvisa) e familiares e pacientes portadores de câncer.

Fabíola de Oliveira (2012) explica que o jornalismo da área científica ainda esbarra em dificuldades, tais como “(...) o difícil acesso às fontes, pois as entidades e a própria comunidade científica, de modo geral, ainda não levam em conta o papel 
estratégico que a comunicação com o público representa para sua própria sobrevivência, salvo raras exceções" (Oliveira, 2012, p. 40). Esse obstáculo pode ser observado durante os últimos meses da cobertura jornalística sobre o caso analisado neste artigo: os pesquisadores detentores da patente da droga passaram a se recusar a dar entrevistas sobre o assunto, principalmente após a denúncia feita pela USP de que Gilberto Chierice teria cometido o crime de curandeirismo.

Entre agosto e outubro, o G1 - São Carlos e Araraquara produziu quatro notícias com aspectos negativos sobre a "pílula do câncer", sendo que, na mesma época, foram publicadas 11 matérias com elementos positivos sobre a droga. Walter Lippmann (2008) afirma que a maioria das impressões que chegam aos cidadãos é um tipo de pantomima apresentado à exaustão. Para ele:

"O número de vezes que nós conscientemente decidimos qualquer coisa sobre eventos além de nossa visão é pequeno, e cada opinião de um homem do que ele poderia realizar, se tentasse, é tênue. Há raramente um assunto prático, e, portanto, um hábito pequeno de decisão. Isso seria mais evidente não fosse o fato de que a maioria da informação quando nos chega carrega consigo uma aura de sugestão de como devemos sentir as notícias. Aquela sugestão nós precisamos, e se nós não a encontramos nas notícias nos voltamos aos editoriais ou a um conselheiro confiável” (Lippmann, 2008, p. 205).

É possível aferir, portanto, que o G1 - São Carlos e Araraquara determinou a maneira como o seu público-leitor vislumbrou a fosfoetanolamina sintética durante os três primeiros meses de sua cobertura jornalística. Com títulos que ofereciam pareceres positivos sobre as cápsulas da USP, o site criou a ilusão de que o composto químico poderia, de fato, trazer benefícios para o tratamento contra o câncer - uma enfermidade que ainda não apresenta cura para todos os tipos.

Os elementos pró-pílula confeccionaram e, de certa forma, reforçaram o tom de "alarmismo" que, muitas vezes, pode ocorrer no jornalismo científico. De acordo com Oliveira (2012, p. 39), “o jornalismo científico (...) resvala muitas vezes no denuncismo e no alarmismo sem fundamento e é incapaz de análises e exposição de contrapontos (tão necessário ao bom jornalismo), como de resto já é corrente na prática do jornalismo econômico e político".

Entre outubro de 2015 e julho de 2016, no entanto, o veículo de comunicação alterou a forma de conduzir a narrativa sobre a fosfoetanolamina sintética, favorecendo o afloramento de uma espécie de desilusão nos indivíduos que viam no suposto medicamento uma possível "cura" ou "milagre". Embora ainda houvesse menções positivas sobre a "pílula do câncer", o número delas começou a declinar quando comparado com o aumento dos pareceres negativos. Nesta investigação, fica nítido que, com a exceção do mês de fevereiro de 2016, o número de títulos negativos às cápsulas da USP é sempre superior ao de positivos.

Os dados também mostram que houve meses sem menções positivas sobre a "pílula do câncer", compreendidos pelos períodos de janeiro, abril e julho de 2016; é importante ressaltar, no entanto, que existiram meses em que não foram citados conteúdos 
negativos sobre a fosfoetanolamina sintética, como é possível notar em fevereiro e junho de 2016 - porém, sempre em menor quantidade em relação às inserções positivas.

Essa construção narrativa reforça o fato de que o portal de notícias alterou a maneira como retratava o caso, criando um foco de desilusão no público-leitor em relação ao composto químico da USP. Os jornalistas do site optavam por informações que levariam à opinião pública a mudar o seu conceito sobre o assunto, tais como autuações por conselhos de classe, obstruções judiciais que impediam que os pacientes portadores de câncer obtivessem o pretenso medicamento, ocorrências de falsificação de fosfoetanolamina sintética, falhas em testes científicos e denúncias de crimes como curandeirismo - que supostamente teriam sido cometidos pelos pesquisadores - entre outros.

Diante dessa mudança, a sociedade que acompanhava os desdobramentos desse acontecimento viu-se frente a um impasse. Isto porque parte do público-leitor acreditava que a mídia estava promovendo uma espécie de "sabotagem" contra os pesquisadores e que também estava bloqueando a esperança de muitos familiares e pacientes portadores de câncer, que viam nessa pílula uma esperança no tratamento contra a doença. Outra parcela do público acreditava que os cientistas necessitavam concluir os testes clínicos para realmente constatar o impacto que essas cápsulas poderiam promover na saúde e bem-estar dos cancerosos, além de serem céticos sobre o fato de que a fosfoetanolamina sintética poderia ser a "cura" para todos os tipos de câncer existentes na atualidade, uma vez que se sabe que a neoplasia tem fundo genético e, por isso, apresenta diversas especificidades que ainda não foram detalhadas e explicadas pela ciência.

Esse embate é possível de ser verificado por meio das falas dos personagens entrevistados pelo veículo de comunicação, bem como pelos comentários postados pelos leitores no site. O parecer também vai ao encontro do pensamento exposto por Motta (2002a), quando ele afirma que a notícia lida com a ambiguidade dos conflitos humanos.

A cobertura jornalística sobre a fosfoetanolamina sintética promovida pelo $G 1$ São Carlos e Araraquara simboliza, na prática, os pensamentos expostos por Beck (2018), quando ele diz que a modernidade tardia deu vasão a duas dimensões de avaliação dos produtos contemporâneos: a "sociedade da segurança" e a "sociedade de risco". Em um primeiro momento, o site deu voz à "sociedade da segurança", ao produzir reportagens que mostravam a droga como um fruto do aperfeiçoamento da ciência brasileira, que poderia, finalmente, oferecer um alento aos cancerosos; por outro lado, após a veiculação do conteúdo televisivo do Fantástico, o website migrou para a dimensão da "sociedade de risco", informando sobre os desdobramentos do fato com cautela e frequentemente dando mais espaço - e, consequentemente, mais importância aos pareceres contrários à droga, além de admitir que o uso de substâncias que ainda não foram aprovadas pela Anvisa pode representar uma ameaça à saúde.

Em suma, é possível constatar que o G1 - São Carlos e Araraquara promoveu a construção de uma ilusão e de uma desilusão no público sobre a fosfoetanolamina sintética. As narrativas oferecidas ao público-leitor pelo site mostram que se criou no 
imaginário da opinião pública a ideia de que o composto químico poderia ser uma medida eficaz contra o câncer, mesmo sem a execução dos testes clínicos. Com o passar dos meses e com a veiculação da reportagem do Fantástico, o portal regional mudou seu posicionamento e o discurso passou de ilusão para desilusão, com a predominância de conteúdos negativos.

\section{Considerações finais}

A narrativa construída pelo G1 - São Carlos e Araraquara durante os primeiros meses de cobertura midiática sobre o caso da fosfoetanolamina sintética se pauta pela criação de uma ilusão nos familiares e pacientes portadores de câncer - bem como no público geral. Há uma indução de pensamento de que a "pílula do câncer" poderia combater a neoplasia ou, pelo menos, apontar para uma possível cura. O uso de termos como "contra o câncer" sugere a ideia de que a substância química desenvolvida nas dependências da Universidade de São Paulo (USP), em São Carlos, poderia trazer avanços científicos para a erradicação da enfermidade, algo que não provou ser verdadeiro conforme os estudos clínicos foram sendo realizados e divulgados na mídia.

Nos primeiros meses e, consequentemente nas primeiras reportagens, o site regional oferecia matérias mais positivas sobre o composto químico, com o uso de personagens e entrevistas com os pesquisadores responsáveis pela substância. Nos últimos meses analisados neste estudo, no entanto, os pesquisadores não são mais entrevistados e há mais manchetes negativas, como os primeiros resultados negativos dos testes promovidos pelo Ministério da Ciência, Tecnologia e Inovação (MCTI), os pareceres contrários da Agência Nacional de Vigilância Sanitária (Anvisa) e a abertura de processo e sindicância pela USP à Gilberto Chierice pelo crime de curandeirismo. Todos esses elementos apontam para uma construção de desilusão em relação a "pílula do câncer", o que acarreta em uma mudança de percepção do público sobre o caso.

A substituição das avaliações positivas pelas mensagens que apontavam a fosfoetanolamina sintética como um medicamento ineficiente e seus responsáveis como produtores de um engodo coloca em evidência a condição do jornalismo e dos jornalistas. Tributários das angústias do contexto cultural em que estão inseridos, em um primeiro momento eles se deixaram envolver pelo desejo de que a cura ou tratamentos mais eficazes do câncer estavam próximos. Em seguida, a desilusão gerada pelas vozes contrárias ao uso da droga e a ausência de comprovação clínica e laboratorial sobre seus efeitos positivos encaminharam para a acusação em série sobre o engano dos responsáveis pela produção da substância.

A reação negativa ao produto capitaneada pela mídia, no entanto, não fez com que parte da comunidade enferma desistisse de reclamar junto à esfera social o direito de obter e continuar usando as cápsulas da USP. A esperança coletiva que a droga auxilie no tratamento do câncer persiste mesmo após a morte de seu principal criador e responsável, o professor Gilberto Chierice, ocorrida em 19 de julho de 2019. No mesmo período, a 
Universidade Federal do Ceará (UFC) anunciou que dará continuidade ao projeto do docente e químico, produzindo novos testes laboratoriais para avaliar a eficácia do produto. Ilusão e desilusão persistem no referente às questões científicas e, especialmente sobre as terapêuticas, e a mídia continuará a fazer a cobertura dos eventos futuros, alimentando esperanças e gerando angústias entre seus consumidores.

\section{Referências}

Bardin, L. (2016). Análise de conteúdo. São Paulo: Edições 70.

Beck, U. (2018). Sociedade de risco mundial: em busca da segurança perdida. Lisboa: Ed. 70.

Fausto Neto, A. (1999). Comunicação e Mídia Impressa: Estudo sobre Aids. São Paulo: Hacker Editores.

Lippmann, W. (2008). Opinião pública. Petrópolis: Vozes.

Morin, E. (2004). A cabeça bem-feita: repensar a reforma, reformar o pensamento. Rio de Janeiro: Bertrand Brasil.

Motta, L. G. (2002a). Explorações epistemológicas sobre uma antropologia da notícia. Revista Famecos, (19), 65-80. Recuperado de http://revistaseletronicas.pucrs.br/ojs/index.php/revistafamecos/article/view/3 $\underline{187 / 2453}$.

Motta, L. G. (2002b). Para uma antropologia da notícia. Revista Brasileira de Ciências da Comunicação, II (25), 11-41.

Mukherjee, S. (2012). O Imperador de todos os males: uma biografia do câncer. São Paulo: Companhia das Letras.

Oliveira, F. (2012). Jornalismo científico. São Paulo: Contexto.

Thompson, J. B. (1995). Ideologia e Cultura Moderna: Teoria Social Crítica na Era dos Meios de Comunicação de Massa. Petrópolis: Vozes.

\section{Notas}

\footnotetext{
i Instituto Nacional do Câncer. (2018). Incidência de Câncer no Brasil. Recuperado de: http://www1.inca.gov.br/estimativa/2018/.

ii Agência Brasil. (2019, 11 de abril). Estilo de vida responde por 63 mil mortes de câncer por ano. Recuperado de: http://agenciabrasil.ebc.com.br/saude/noticia/2019-04/estilo-de-vida-respondepor-63-mil-mortes-de-cancer-por-ano-no-brasil.
} 
iii Fundação Instituto Oswaldo Cruz, principal centro de pesquisas médicas do Brasil. iv Tribunal de Justiça do Estado de São Paulo.

v Geraldo Alckmin, governador do Estado de São Paulo no período.

vi Fundação para o Remédio Popular, laboratório farmacêutico ligado ao governo do Estado de São Paulo.

vii Ministério da Ciência e Tecnologia e Inovação.

viii Tribunal Regional Federal.

ix Estado do Mato Grosso do Sul, no Brasil.

x Fantástico. (2015, 18 de outubro). Drauzio Varella alerta sobre cápsulas distribuídas

como cura do câncer. Recuperado de: http://g1.globo.com/fantastico/noticia/2015/10/drauzio-varella-

alerta-sobre-capsulas-distribuidas-como-cura-do-cancer.html. 